\title{
How Will Open Science Impact on University-Industry Collaboration?
}

\author{
Joanna Chataway ${ }^{\text {a }}$ \\ Professor of Science and Technology Policy, Science Policy Research Unit), J.C.Chataway@sussex.ac.uk \\ Sarah Parks ${ }^{\text {b }}$ \\ Senior Analyst, Innovation, Health and Science Group, sparks@rand.org \\ Elta Smith ${ }^{\mathrm{b}}$ \\ Associate Director, Innovation, Health and Science Group, eltas@rand.org \\ ${ }^{a}$ University of Sussex, Sussex House, Falmer Brighton, BN1 9RH, United Kingdom. \\ ${ }^{\mathrm{b}}$ RAND Europe, Westbrook Centre/Milton Rd, Cambridge CB4 1YG, United Kingdom.
}

\begin{abstract}
$\mathrm{O}$ pen science represents a challenge to traditional modes of scientific practice and collaboration. Knowledge exchange is still heavily influenced by researchers' ambitions to publish in highly cited journals and within "closed partnerships", where interactions are based upon intellectual property rights. However, perceived inefficiencies, a desire to make publicly funded research available to all and a crisis of confidence in the quality of research published in top journals all

serve to fuel demands for more openness in the conduct of science and the exchange of scientific knowledge. Whilst there is a strong logic behind the contention that increased openness will promote efficiencies, quality and fairness, there is still considerable uncertainty about the impact on university-industry collaboration and the balance that needs to be struck between open and closed approaches. Policy obstacles are also likely to impede the pace of change.
\end{abstract}

Keywords: open science; open access; knowledge exchange; university/industry collaborations; science policy; research funders.
Citation: Chataway J., Parks S., Smith E. (2017) How Will Open Science Impact on University-Industry Collaboration? Foresight and STI Governance, vol. 11, no 2, pp. 44-53. DOI: 10.17323/2500-2597.2017.2.44.53 
C alls for research to be made "open" are gaining momentum. Funders have been particularly active in demanding change. Although they vary in the degree of openness required and in their interpretation of what a more open approach actually entails, there is now a near consensus that, at the very least, open access must apply to published research results and some funders increasingly require access to research data as well. In addition to funder requirements, other drivers of increasing openness include calls from a variety of stakeholders including researchers themselves for more transparency and less duplication in research.

It is too early to give a definitive answer to the question posed in the title of this article. However, asking the question at this time is a useful exercise as it encourages us to reflect upon the current situation and begin to analyze current trends, drivers and enablers related to open-science-based collaboration as well as obstacles and tensions associated with open and global access to science. This article endeavours to begin that work and to identify some of the policy challenges associated with moves towards more open science. The study is structured around a number of sub-questions to the title's overall question and concludes with some reflections on the implications for policy-making.

\section{Are we moving away from traditional models of S\&T-based university- industry collaboration?}

Over the course of the past century, the professionalization of science has seen been associated with the emergence of specific organizational and institutional centers of scientific activity. Scientific activity has overwhelmingly taken place at universities or other research organizations, government laboratories or at research and scientific facilities supported by private companies. Norms have emerged that provide the basis for career development and incentives and have also come to define "excellent" research. The infrastructure of knowledge-generating and -diffusing institutions provide a powerful embodiment of Western science's ambition to produce more of this knowledge. The world's best universities and leading scientific journals have reflected a deeply engrained understanding of how excellence is produced and how it is shared [Chataway, Smith, 2007].

Patterns of interaction and knowledge exchange between organizations and institutions have also been underpinned by well-established norms and increasingly in R\&D-intensive sectors, by intellectual property rights. There have been periods and specific instances of data sharing and collaborative approaches, which run counter to the usual restrictions on ownership and governance structures, but these have usually been associated with security issues and national emergencies. Outside of these particular circumstances and periods of time, for the most part the extent to which data have been generated or shared has been regulated by professional norms and by various forms of copyright and intellectual property protection. Collaboration between companies and universities has increasingly been built upon IP agreements and other mechanisms to facilitate partnership in order to protect investments made during the early stages of research [Arora, Athreve, 2012].

The premise of these arrangements is that universities produce scientific knowledge that, once patented and perhaps published in leading journals, can be transferred and commercially exploited by new or existing companies. A recent article described this era of knowledge transfer and exchange as "closed partnerships" [Holmes, 2016] and argued that this arrangement was typical in the 1980s. However, this formula has been modified in recent decades, supplemented with other forms of partnerships and in some cases replaced with more open arrangements [Ibid.]. The closed exchange model is no longer assumed to be the most efficient way of sharing results. Furthermore, the debate about the impact more open science might have on university and industry relations points to several areas where the evidence is ambiguous and uncertain.

First, a number of academics and analysts have pointed out that the majority of innovation does not depend on outputs from R\&D [NESTA, 2007]. Most changes in patent restrictions and open access approaches that reveal early research findings in an accessible way would not have a negative impact on the interactions between universities and industry, in the sense of a decrease in the quantity or quality of exchanges, because tacit knowledge is and always has been at the heart of successful relationships [Nelson, 2004]. In addition to this, there is a mounting of body of evidence that questions whether the traditional model is actually the most efficient way of organizing the production of scientific knowledge and whether it is effective in underpinning product development and innovation. We will look briefly at two areas where there has been a critique of restricted access to knowledge. The first area relates to intellectual property rights (IPR) and the second concerns access to publications.

\section{What is the impact of IPR on innovation? Do the tragedy of the anticommons and perceived inefficiencies outweigh the benefits?}

The use of IPR has been an important component of innovation policy for many years. The history of IPR and innovation policy is long and complex. It is not our intent to review or summarize that history here. Our aim is limited to highlighting the increasingly contentious notion that patenting, especially as it applies to early research results and tools, fosters innovation. Most of our examples are from the life sciences field. This is the sector where the debate about patenting has been the most intense and it is a sector where experimentation in open science and open innovation is particularly evident. 
In recent decades, the rate of patenting has increased significantly across a range of sectors and particularly in the life sciences [Owen-Smith, Powell, 2003; Bubela et al., 2013]. The causes of this rise in patenting activity are complex and differ somewhat across sectors. One of the drivers behind the move to early patenting in both the public and private sectors is increasing financial pressures [Morgan Jones et al., 2014]. In areas such as biotechnology, innovation is largely rooted in industrial structures that depend on patent-backed finance and this has fuelled what some analysts consider an unproductive tendency to hype patented research results and tools, which subsequently lead to investors becoming disillusioned with the sector [Hopkins et al., 2007; Owen, Hopkins, 2016].

A number of authors have questioned the effectiveness of patenting at an early stage more generally [Marshall, 2012; Eisenberg, 2012], noting that patenting may reduce incentives and capacities to share knowledge. Michael Heller deploys the term "the tragedy of the anticommons" to refute a longstanding contention that common property will be neglected and will not generate the expected returns to a community over the long term [Heller, 1998].

In more recent years, the modeling of anti-commons behavior has been used to dispute the efficacy of patenting across a range of sectors including biotechnology [Burk, Lemley, 2009; Heller, 2016]. Nelson [Nelson, 2004] argues that technological advancement is an evolutionary process, and as such, benefits from the development of knowledge via multiple pathways by a number of different actors. It is also cumulative, as bodies of knowledge build on previous understandings. The scientific community, Nelson claims, should not be hindered in working freely with and from new scientific findings because of the long-term and public good benefits that come to society from investment in basic research.

Patents on early stage research, in particular, can prove costly and bureaucratic, and this has direct as well as less obvious impacts on the rate and direction of research. One of the less obvious consequences is that researchers may need to weigh the costs of accessing tools and techniques to enable them to undertake research and this makes them more risk-adverse. This is a problem for both public and private sector scientists.

Although IP provides a route for start-up companies to raise financing and is therefore seen by many as enabling innovation, the impact of reliance on IP for financing also constrains what companies are able to do [Tait, Chataway, 2007]. This has led proponents of open science approaches to question the degree of risky innovation that organizations, which are highly dependent on patenting, can undertake. Aled Edwards from the Structural Genomics Consortium says:

Industry scientists do not have the opportunity to focus their efforts on discovering new validated targets and mechanisms. More often, they develop innovative ways to tackle established ("validated") drug discovery mechanisms. This situation arises because there is a disconnect between drug discovery timelines (5-10 years) and the need for biotech investors to recoup their investment (2-5 years) [Edwards, 2013].

Edwards concludes that because biotech firms are dependent on IP-related finance, they can never be the source of more radical and risky innovation.

\section{Should we be concerned about the efficiency and quality of mainstream science?}

A paper appearing in Nature in 2012 [Begley, Ellis, 2012] by researchers from the pharmaceutical company, Amgen, raised a set of concerns about the quality of science being produced in top journals and the extent to which that "excellent" science could actually be used in innovation and product development. The article reported that a large percentage of cancer-related studies that Amgen researchers tried to replicate were not reproducible. Begley and Ellis question the incentive frameworks that academics work within and question whether peer review is an effective mechanism for assessing the quality of scientific output and evaluating grant applications. The authors suggested that bad practice are not checked and may actually be encouraged under the current system: "...the academic system and peer-review process tolerates and perhaps even inadvertently encourages such conduct. To obtain funding, a job, promotion or tenure, researchers need a strong publication record, often including a first authored high impact publication. Journal editors, reviewers and grant giving-review committees often look for a scientific finding that is simple, clear and complete - a 'perfect' story. It is therefore tempting for investigators to submit selected data sets for publication, or even to massage data to fit the underlying hypothesis" [Begley, Ellis, 2012]. Even diligent peer review commissioned by the best journals will not be able to detect the problems that arise from this behavior.

In an introduction to a recent series of papers on increasing value and reducing waste in healthcare research, the editors of The Lancet, a leading healthcare research journal, reflected on Randy Schekman's critique of standards in "luxury" journals such as Nature, Science and Cell. According to Schekman, a Nobel prize laureate, the reputations of these journals rest upon the unwarranted notion that they publish uniformly excellent research. He asserted that they are far from the only outlets for outstanding research. The Lancet editors produced a special issue that tried to look more broadly at the following question: "How should the entire scientific enterprise change to produce reliable and accessible evidence that 
addresses the challenges faced by society and the individuals who make up those societies?" [Kleinert, Horton, 2014].

One of the articles in the special issue analyzes the cost of R\&D and the losses associated with conventional methods of producing knowledge. Costs associated with $\mathrm{R} \& \mathrm{D}$ have risen annually and current expenditure on a global basis was estimated at US $\$ 240$ billion a year in 2010 [Chalmers et al., 2014]. Basic research is the principle beneficiary of this investment. More than half of $£ 1.6$ billion of public and charitable investment in research in the UK was spent on basic research in 2009-2010, and this pattern was also observed in the US. While researchers often want to work on basic research and "luxury journals" want to publish breakthrough findings, there appears to be strong evidence emerging that basic research is not responsible for major successes in medical innovation in the way that earlier analysts assumed that it was [Chalmers et al., 2014]. In 2009, Chalmers and Glasziou estimated that the cumulative effect of avoidable losses in biomedical research means that about $85 \%$ of research investment - equating to $\$ 200$ billion of the investment in 2010 - was spent ineffectively [Chalmers, Glasziou, 2009]. Using a narrower measure of waste, Freedman et al. estimate that the cost of the lack of reproducibility in life sciences is $\$ 28$ billion [Macleod et al., 2014; Freedman et al., 2015]. The complex set of factors that produces this situation is related to an incentive structure that promotes secrecy, a lack of openness and a fixation on publishing in high-impact journals.

\section{What is open science and might it help produce scientific knowledge more efficiently and effectively?}

There are changes taking place that may help counteract some of the problems associated with our current "conventional" modes of performing and rewarding research. This transformation is happening across the whole research process, from the way public research agendas are set to the way results are shared with other researchers and the public. These changes are neither uniform across the research process nor are they equally shared amongst disciplines, but collectively they appear to be having fundamental effects on the research system. Together, these changes are often referred to as open science and they represent what might be best described as a movement of researchers and others involved in scientific research, that, in some respects, runs counter to, but is also effectively evolving from the traditional model of scientific research.

Open science is most frequently and closely associated with how research is conducted and how the results are disseminated. Open access to scientific publications is the most well-known aspect of the open science movement, whereby research outputs - typically journal articles - are made freely available, without access fees and increasingly with fewer copyright and licensing restrictions. As an example, Randy Scheckman, the Nobel prize winner mentioned earlier, has since established an online open access journal that defines itself as existing outside of the framework assessing impact factor.

Worldwide, the proportion of papers published with open access in 2011 was about $44 \%$, up from $38 \%$ in 2004, taking this practice well into the mainstream of research [Archambault et al., 2013]. Many researchers and increasingly policymakers aspire to open access becoming a standard feature of the research process [Netherlands EU Presidency, 2016]. The EU Competitiveness Council has already concluded that all scientific articles should be open access by 2020 [Council of the European Union, 2016].

Open science also refers to an increase in researchers making the data underpinning research results freely available online. Some of the most prominent examples have emerged from large-scale public health crises. For example, data sharing of genome analyses to tackle the Ebola epidemic was widely seen to have enabled geneticists and evolutionary virologists to work together to confirm the origin and transmission mode of the virus as well as the estimated routes of infection and predicted rates of mutation. This information supported crisis management efforts by local and international public health organizations by showing them where to focus their relief efforts and enabling them to develop practical advice to limit the spread of infections. Data sharing also helped both the public and private sectors to more quickly design new therapies, diagnostics kits and vaccines. Besides Ebola ${ }^{1}$, similar efforts have been undertaken to combat the Zika virus outbreak and malaria. ${ }^{2}$ Indeed, there is emerging evidence that where data sharing failures do occur, progress in addressing the problem is slowed or hindered, as demonstrated during the outbreak of Middle East respiratory syndrome (MERS) in Saudi Arabia, where disputes over intellectual property rights created barriers impeding access to samples [Yozwiak, 2015].

Online repositories have emerged in recent years to collect and make researchers' data available. Zenodo is an example at the other end of the spectrum from the international efforts to address the major diseases cited previously, focusing instead on the "long tail" of small-scale research results that are not otherwise part of existing institutional repositories. Zenodo invites submissions from any discipline and particularly encourages multidisciplinary contributions.

Researchers have also increasingly begun to share their code, software, and lab books. For example, GitHub has become an important source of open code and for the development of open software, citing

\footnotetext{
${ }^{1}$ www.eboladata.org.

${ }^{2}$ www.opensourcemalaria.org.
} 
15 million users across 38 million records on the site 3 . The overall effect of this "opening up" in the research process means that researchers are communicating more freely and transparently and at earlier stages in the research process, to generate new ideas, find collaborators, define research methodologies and analyze their results. This should lead to the greater use and reuse of data, the earlier identification of problems, and improved and more rapid development of research tools. This may well mean that open science can address some of the challenges with as much efficiency as the traditional, mainstream model. Open science can also resolve problems associated with low reproducibility and poor quality that can occur through more traditional research approaches. Open peer review can include a disclosure of information about the peer reviewer (as opposed to anonymization) and a publication of the contents of the review. Open peer review can also refer to allowing unsolicited peer review. Alongside more freely available data and access to research results, being able to assess the contents of a peer review could help others identify the bad practices and "too perfect" stories that can be told when this information is not available. Online forums and social media allow scientists to quickly uncover high-profile studies with major underlying flaws, such as the "discovery" of arsenic-based life [Hayden, 2012].

Other initiatives aim squarely at the problems associated with the lack of reproducibility identified in many disciplines. A leading example from psychology, the Reproducibility Project, involved 270 scientists in trying to reproduce the key findings of 100 articles published in three leading psychology journals, which found that only 30-50\% could be replicated [Aarts et al., 2015]. From the perspective of "opening up" the scientific process, this project not only prioritized correspondence and collaboration with the original authors, but also encouraged the authors to publish the results in an open access format and made the underlying datasets available for others to use in the future. A similar effort is being undertaken in other disciplines, such as cancer biology, with the effect of highlighting the importance of replication in the advancement of science. Innovation is important, but without replication one cannot verify new findings, and therefore we can never be certain whether we actually "know what we think we know" [Ibid].

A final potential corrective to the traditional model of scientific research enabled through open science is increasing the support given by non-professionals and multi-disciplinary researchers during the research process. Crowdsourcing is the archetypal example whereby an often undefined set of people the "crowd" - is called upon to help solve problems or contribute to other aspects of the research process, including correcting mistakes and raising money. This support may range from generating research ideas to data gathering, problem-solving and decision-making either in a collaborative way or through independent contributions. Foldit is one example, involving an online game about protein folding; the highest scoring submissions are analyzed by researchers to determine whether the configuration is applicable to proteins found in nature. A study of the outcomes of the Foldit approach, published in 2010 [Cooper et al., 2010], found that the solutions identified by gamers were better than those generated by a computer algorithm. The solutions could be used to develop new biological innovations or cure diseases. In many cases, the people who participate in these projects would not traditionally be considered "experts" in the field to which they are contributing, while in others, crowdsourcing enables the engagement of researchers who may not otherwise have had the opportunity to participate. The Reproducibility Project is one such example of the latter. In most cases, participants are recruited online through an open call. This reduces the logistical problems associated with having participants travel to a centralized location and enables the call to reach a wider set of potential participants.

Proponents of open science argue that these activities can increase transparency, collaboration, communication and participation in scientific processes. They could help remove disciplinary barriers and encourage greater interaction between "science" and "society". They could also speed up the scientific process by tapping into the critical mass necessary to generate ideas, increase the efficiency of the process, and facilitate the validation or rejection of theories.

Digital technology enables many of the developments that are considered part of open science, but technology alone is not responsible for the size and scale of activities in this area. Open science is also strongly supported by those who believe in the value of freely circulating knowledge and freely circulating critiques of that knowledge, and interest in the role, value and function of data in the research process.

\section{Are we moving towards a new era?}

The dynamics between advocacy, technological progress and institutional change are interesting to consider when reviewing the progress of open science. The power of advocacy and social movements is a key factor in health innovation. The history of drug development is full of examples of progress rooted in the advocacy for patients and patient organizations [Chataway et al., 2010; Marjanovic et al., 2015]. The targeted allocation of resources and incentives for organizations to work together resulted in significant investments in the treatment of HIV/AIDS and for certain kinds of cancer [Taylor et al., 2015]. Whilst the momentum behind open science grows, evidence concerning the costs and benefits lag behind. The

\footnotetext{
${ }^{3}$ https://github.com/.
} 
extent to which open science will transform relationships is likely to depend both on the strength of advocacy and evidence in a number of areas.

\section{What is the optimal balance between openness and ownership?}

The issue of whether various forms of open science contribute to more effective science (improving the rate of output) or to more efficient science (improving the external effects or, in other words, the degree to which that science is used by target audiences) will be important in determining the extent to which it takes root institutionally.

Some benefits of open science are easier to calculate than others. The value of data repositories has been examined and studies suggest that its economic value is clear [Lateral Economics, 2016]. This still leaves ambiguity, however, with regard to the extent to which open science and innovation are associated with economic efficiency and value creation. The evidence on that assertion remains unclear. It is true, however, that there is a clear logic that argues for more efficiency in many cases. In drug development, where patenting is still the norm and where the costs of research are so high, the argument that open science could reduce duplication is particularly convincing. A more open approach would reduce the extent to which companies conduct identical or similar research behind closed doors. This is particularly important because companies tend not to publish failed studies. This means that other groups are likely to follow the same routes of enquiry without knowledge of the previous unsuccessful attempts.

On this point, Pierre Meulien, head of the Innovative Medicines Initiative (IMI), is quoted in Nature as saying: "If ten companies are working on Alzheimer's disease on exactly the same target and it's failed, that's ten times the investment that is down the tubes" [Savage, 2016]. This duplication and unproductive replication of research may well underlie much of the unjustified losses identified by Glasziou and Chalmers in a study referred to earlier in this article [Glasziou, Chalmers, 2009].

Many proponents of more open approaches feel that the most significant contributions of open science will come from knowledge gains. Sharing the investments and opening channels for knowledge exchange will lead to a greater understanding and the generation of research results in areas that were previously deemed too risky and expensive [Morgan Jones et al., 2014; Savage, 2016]. Moreover, open partnerships facilitate greater knowledge exchange between public and private sector researchers, each of whom bring a different focus to the science and development of research [Morgan Jones et al., 2014].

If the logic behind the arguments that more open approaches will generate overall benefits, particularly in the early stages, seem strong, an important question still remains concerning how economic benefits from research will be shared. This issue becomes more acute at later stages of applied research, when in drug development, for instance, research costs rise dramatically. Members of the SGC team have tried to develop more downstream approaches and have had much more difficulty in making openness work in this context [Savage, 2016].

While an evidence base is emerging to help us identify the benefits of more open approaches, there remains a great deal of uncertainty about the nature of those benefits. If this is the case in basic science, it is amplified in more applied research, where there is a very high degree of uncertainty about the balance that should be struck between open science and patenting, which would help ensure a return on investment. The move to more openness has been hampered by this lack of evidence.

\section{Academic career paths: Will open science work for university scientists?}

Current career paths and researcher evaluation methods do not necessarily encourage open science. Academics often need to point to high impact publications in journals that are not open access. There is mixed evidence about how university scientists experience the push towards open science. This is potentially an important subject for a discussion about how university-industry collaboration might evolve.

Some evidence suggests that open science activities tend to be considered time-consuming, and not necessarily as rewarding career-wise as traditional research. In a 2014 public survey on Science 2.0 (now known as "Open Science"), $88 \%$ of respondents cited a perceived lack of credit for researchers involved in open science activities as a barrier to open science itself [European Commission, 2015]. This was the second largest barrier for individual scientists. Other barriers included uncertain benefits for researchers and a lack of financial support for those activities.

Concerns about the effects of open science activities on careers vary depending on the respondent's career stage. A 2014 knowledge exchange report on data sharing found that early career researchers feared getting scooped (having results published by someone else before the researcher has published them) and the potential embarrasment of publishing immature or potentially inaccurate data. Mid-career researchers did not fear embarrassment, but did worry about their research results getting scooped. Further, they hoped to maximize the number of publications they could get from a data source and hence may not have wanted to share it [van den Eynden, Bishop, 2014].

Despite these concerns, evidence is growing and it demonstrates that embracing open science practices can improve careers. A recent review highlighted a number of small but potentially important effects 
on researchers' careers [McKiernan et al., 2016]. These included the fact that open access publications receive more citations and more media attention than closed access papers. Open research practices can help researchers find collaborators and open up possible job and funding opportunities. For example, Publons, a website where researchers can register their peer-reviews including whether or not they were open, produces a report that researchers can put on their CV to display their activity in general and their level of openness. ${ }^{4}$ The journal Psychological Science has introduced badges attached to papers if the paper provides links to open data or open materials. Early evidence suggests these badges encourage openness [Kidwell et al., 2016].

\section{Is the increasing fragmentation of initiatives a problem?}

Policies encouraging open science, and in particular open access, have taken off and multiplied over the last ten years. As of July 2016, ROARMAP, ${ }^{5}$ which records open access policies and mandates worldwide, contains 779 policies; 133 of these are funder policies (54 of these funders also carry out their own research), and the other 636 are held by research organizations or sub-units of research organizations. European institutions hold 463 of the 779 policies. These policies vary greatly between and within research organizations and funders, with differences including:

- Whether open access is mandatory or encouraged,

- Priority of green or gold publishing ${ }^{6}$, and

- Whether temporary embargos are permitted.

The Pasteur4OA report on open access policies [Swan et al., 2015] highlights the need for aligned policies, noting that researchers may receive funding from more than one funder, and if there is a significant difference between policies, there may be conflicts. Due to the large variety of open access policies and the lack of evidence about what constitutes a good one, there are ongoing efforts to compare policies and develop a measure of the "strength" of a policy [Vincent-Lamarre et al., 2016]. This could then help R\&D funders develop more unified and effective policies.

Other aspects of open science policy are currently less developed and appear fragmented. Declarations regulating data sharing are not as numerous as those regulating access to research publications, but they are no less diverse. Funding organizations are not only ones whose policies affect researcher activity. Institutions and publishers also have policies on open access and data sharing. This means that when a researcher wishes to publish an article, they must understand the policies of their funder(s), the institutions and their chosen publishing location, as well as work out how to satisfy all three at the same time.

\section{Do we need new policy tools, including indicators and monitoring tools?}

Open science initiatives are in line with many researchers' own beliefs about the importance of knowledge exchange and collaboration. They are being pursued in earnest by the researchers themselves through grassroots-style efforts to build online communities to share information and ideas. At the same time, funders, publishers, industry and citizens are closely engaged in open science activities, driving their development at multiple levels. Recently, the movement has furthermore received serious attention from governments and other institutions worldwide. In the U.S., the White House Office of Science and Technology Policy has developed measures to increase public access to federally-funded research results ${ }^{7}$. The EU has gone even further, making it one of three main priority areas for the European Commission's science, research and innovation policy [Moedas, 2015]. The EU and its member states have acted to facilitate open science in some areas, such as open access to research publications, which is required by EU policy. Open data policies and infrastructure development are under discussion. For example, a pilot initiative, Open Research Data, was launched under Horizon 2020. Some of the most relevant issues underpinning open science have been addressed on the European Research Area agenda [European Commission, 2012a] and reflected in European Commission recommendations on access to and protection of scientific data [European Commission, 2012b]. Such measures are designed to improve access to scientific information produced in Europe.

Despite the momentum building around it, the movement toward open science is still in its infancy. Acknowledging this, the European Commission set up the Open Science Platform in 2016, which is composed of representatives from all European states participating in open science initiatives ${ }^{8}$.The Platform was designed to provide expert advice to the Commission about how to develop and implement open science policy. It guarantees that any policy initiatives are based on an informed view of the benefits and drawbacks of open science, which increases efficiency and lowers costs.

\footnotetext{
${ }^{4}$ https://publons.com/.

5 https://roarmap.eprints.org/.

${ }^{6}$ Where gold refers to an article being published open access in a journal, and green refers to the article being deposited in an Open Access repository after publication in a subscription journal.

U.S. OSTP (ND) "OSTP Public Access Policy Forum”, https://www.whitehouse.gov/administration/eop/ostp/library/ publicaccesspolicy.
} 
There is a real need to better understand where open science activities are concentrated: in countries, amongst disciplines and at different stages of the research process. It is still too early to really begin to measure the impact of efforts in this area. As such, there is potential for developing monitoring tools that can help one track trends in open science as an initial step towards informing policy-making in this area. Over time, as the effects of this model begin to be understood, monitoring activity can serve as a foundation for assessments of open science achievements.

The key characteristics of open science, such as free access to scientific publications and databases, must be further studied. In order to meet this challenge, the EU has begun to build an open science monitor, which is developing indicators that can illustrate open science trends at all levels of the research process: from idea generation and funding to data collection, analysis and the publication of research findings [Smith et al., 2017]. Such a monitor can help the European Commission and its advisors better understand how open science is evolving in Europe and in other parts of the world. This will allow them to focus on areas where the most impact can be achieved through policy initiatives.

\section{Policy challenges}

Growing support from research funders and policymakers suggest that the momentum behind open science is likely to continue building. This article has outlined mounting evidence that open science presents a convincing alternative to traditional models of scientific activity and the conventional metrics used to define academic success and career progression. We tried to set out some of the key questions and issues underlying the rate and direction of change in open science. In conclusion, we argue that the impact on industry-university collaboration will rest on several key assessments made by stakeholders and policymakers.

First, to date there have been relatively few evaluations of the costs and benefits of open access approaches to publications and data. There have been some assessments of individual schemes such as those carried out by the Structural Genomics Consortium (SGC) and RAND Europe [Morgan Jones et al., 2014]. However, decision making would be facilitated by studies that span initiatives and develop broader frameworks and criteria for evaluation. Many in both the private and public sectors naturally view the move to open data sharing as extremely risky and think that the extent of benefits gained will depend on the particular contexts in which open science approaches are implemented [Morgan Jones et al., 2014]. The rate and direction of moves towards more openness, and the success or failure of the movement as a whole, are likely to be affected by the nature of evidence produced over the coming years. Steps taken by the EU to build a monitoring mechanism are extremely constructive in this respect.

Second, researcher attitudes to open access publishing will to some extent depend on the way that they are assessed. In the UK and other countries, evaluations of the performance of university-based researchers have begun to change [Manville et al., 2015]. The Research Excellence Framework (REF), which for the first time assessed research and allocated funds on the basis of academic and non-academic research, could potentially break down the nexus of factors underpinning academics' overwhelming concern about publishing in high impact journals. If university researchers can point to a variety of indicators to support claims of excellence and impact, the incentive to publish in those journals would be undermined to some extent and make publishing in open access journals more appealing. There is also some evidence that open access journals have more citations than their traditional counterparts, and this may influence university researchers' choices.

The REF is beginning to change the way in which UK universities reward and promote academics [Stern, 2016]. Nevertheless, the weight of long-standing traditions of a culture that measured research activity according to quite a narrow set of academic achievements means that the system is unlikely to change smoothly or rapidly.

With regard to the impact on university-industry collaboration, many questions still remain. While the logic behind the potential benefits of open access publishing are clear, there is limited empirical evidence about how it influences companies' absorption of research results. Monitoring and evaluation tools are needed both to clarify the situation as it exists and to provide evidence for better decision making. If this is true for open access, it is even more relevant for open data approaches, which may well have greater implications for patent activity. The extent to which universities support more open approaches will depend in part on how the broader community feels about open access and open data. The pace and direction may well be impacted by the availability of evidence, which can be used to support the move to openness. Steps are being taken to gather evidence about the impact of open access and data repositories, but there are numerous difficulties associated with the exercise and endeavors are still at a relatively early stage [Keserü, 2015].

There is still uncertainty regarding the future of non-academic metrics and the role they will play in policy. The UK is committed to the continued use of non-academic metrics and is encouraging the development

\footnotetext{
${ }^{8}$ http://ec.europa.eu/research/openscience/index.cfm?pg=open-science-policy-platform.
} 
of a broader range of assessment metrics [Stern, 2016]. Other European and US institutions are interested in similar policy trajectories [Guthrie et al., 2013]. However, the UK appears to be the frontrunner in introducing a national scheme that bases funding allocations on broader impact metrics, and the extent to which other countries will follow remains unclear.

One of the unintended consequences of the growing enthusiasm for open science is the plethora of initiatives that are being undertaken to promote and support relevant activities. As we have pointed out, initiatives and policies are issued not only by a wide range of different funding bodies but also by some universities and publishers. Whilst this is good news for those supporting open science in some respects, it could be that the fragmentation and confusion surrounding policies undermine long-term development in this area. If the complexity adds to transaction costs, it may even inhibit the development of open science-based partnerships and collaboration. This danger is particularly relevant for partnerships between universities and businesses. Work on the Structural Genomics Consortium indicates [Morgan Jones et al., 2014] that the opportunity to conclude agreements that are as simple and transparent as possible encourages companies to engage in collaboration. However, if various organizations and institutions begin to impose a wide range of different standards, one of the main advantages for partners to engage in collaboration may be nullified. The ability of funders and policymakers to define a coherent and shared agenda is likely to be an increasingly important factor in the way in which open science evolves. Of course, this agenda would ideally be based on an evaluation of the various approaches and the evidence-based development of more standardized approaches. However, political and interest-based considerations may likely play some role in determining the future shape of open science policies. It will be vital for those interested in using open science to structure university-industry collaboration in such a way that it is possible to monitor the developments and support approaches that serve the interests of all parties for sustainable and useful cooperation.

A version of this article will appear in the book Innovation and the Entrepreneurial University, to be published by Springer (eds: E. Erdil, D. Meissner and J. Chataway).

\section{References}

Archambault E., Amyot D., Deschamps P., Nicol A., Rebout L., Roberge G. (2013) Proportion of Open Access Peer-Reviewed Papers at the European and World Levels-2004-2011, Brussels; Montreal; Washington: ScienceMetrix Inc. Available at: http://www.science-metrix.com/pdf/SM_EC_OA_Availability_2004-2011.pdf, accessed 24.02.2017.

Arora A., Athreye S. (2012) Patent Incentives: Returns to Patenting and the Inducement for Research \& Development (Intellectual Property Office Research Paper no 2012/20, November 2012), Newport (UK): Intellectual Property Office.

Begley C.G., Ellis L.M. (2012) Drug development: Raise standards for preclinical cancer research. Nature, vol. 483, pp. 531-533.

Bubela T., Gold E.R., Graff G.D., Castle D. (2013) Patent Landscaping for Life Sciences Innovation: Toward Consistent and Transparent Practices. Nature Biotechnology, vol. 31, no 3, pp. 202-206. DOI: 10.1038/nbt.2521.

Burk D., Lemley M. (2009) The patent crisis and how the courts can solve it, Chicago: University of Chicago Press.

Chalmers I., Bracken M.B., Djulbegovic B., Garattini S., Grant J., Gülmezoglu A.M., Howells D.W., Ioannidis P.A., Oliver S. (2014) How to increase value and reduce waste when research priorities are set. Lancet, vol. 383, no 9912, pp. 156-165.

Chalmers I., Glazsiou P. (2009) Avoidable waste in the production and reporting of research evidence. Lancet, vol. 374, pp. 86-89.

Chataway J., Smith J. (2007) Shaping scientific excellence in agricultural research. International Journal of Biotechnology, vol. 9, no 2, pp. 172-180.

Chataway J.C., Hanlin R., Mugwagwa J., Muraguri L. (2010) Global health social technologies: Reflections on evolving theories and landscapes. Research Policy, vol. 39, no 10, pp. 1277-1288. Available at: http://dx.doi.org/10.1016/j. respol.2010.07.006, accessed 19.06.2016.

Cooper S., Khatib F., Treuille A., Barbero J., Lee J., Beenen M., Leaver-Fay A., Baker D., Popovic Z. (2010) FoldIt Players. Predicting protein structures with a multiplayer online game. Nature, vol. 466, pp. 756-760.

Council of the European Union (2016) Outcome of proceedings of May 27, 2016 - RECH 208 TELECOM 100, 9526/16, Brussels. Council of the European Union: Available at: http://data.consilium.europa.eu/doc/document/ST-9526-2016INIT/en/pdf, accessed 13.10.2016.

Edwards E. (2013) The prevailing view in biomedicine and drug discovery is that we need more "innovation". Available at: http://www.thesgc.org/blog/biotech-and-innovation, accessed 19.06.2016.

Eisenberg R.S. (2012) Wisdom of the Ages or Dead-Hand Control? Patentable Subject Matter for Diagnostic Methods After In Re Bilski. Case Western Reserve Journal of Law, Technology and the Internet, vol. 3, no 1, pp. 1-65.

European Commission (2012a) Commission Recommendation of 17 July 2012 on access to and preservation of scientific information (COM(2012) 4890 final), Brussels: European Commission. Available at: https://ec.europa.eu/research/ science-society/document_library/pdf_06/recommendation-access-and-preservation-scientific-information_en.pdf, accessed 19.08.2016.

European Commission (2012b) Communication from the Commission to the European Parliament, the Council, the European Economic and Social Committee and the Committee of the Regions: A Reinforced European Research Area Partnership for Excellence and Growth (COM(2012) 392 final), Brussels: European Commission. Available at: http:// ec.europa.eu/euraxess/pdf/research_policies/era-communication_en.pdf, accessed 19.08.2016.

European Commission (2015) Validation of the results of the public consultation on Science 2.0: Science in Transition, Brussels: European Commission. Available at: http://ec.europa.eu/research/consultations/science-2.0/science_2_0_ final_report.pdf, accessed 19.06.2016.

Freedman L.P., Cockburn I.M., Simcoe T.S. (2015) The economics of reproducibility in preclinical research. PLoS Biology, vol. 13, no 6, e1002165. DOI: 10.1371/journal.pbio.1002165. Available at: http://journals.plos.org/plosbiology/article/ file?id=10.1371/journal.pbio.1002165\&type=printable, accessed 19.08.2016. 
Guthrie S., Wamae W., Diepeveen S., Wooden S., Grant J. (2013) Measuring research: A guide to research evaluation frameworks and tools, Santa Monica, CA: RAND Corporation. Available at: http://www.rand.org/pubs/monographs/ MG1217.html, accessed 19.08.2016.

Hayden E.C. (2012) Study challenges existence of arsenic-based life. Nature News, January 20. Available at: http://www. nature.com/news/study-challenges-existence-of-arsenic-based-life-1.9861, accessed 19.08.2016.

Heller M. (1998) The Tragedy of the Anticommons: Property in the Transition from Marx to Markets. Harvard Law Review, vol. 111, pp. 621-688.

Heller M. (2016) The Tragedy of the Anti-Commons. Available at: http://www.countercurrents.org/2016/08/13/the-tragedyof-the-anticommons/, accessed 19.08.2016.

Holmes D. (2016) A new chapter in innovation. Nature, vol. 533 (May 2016), p. 54.

Hopkins M.M., Martin P.A., Nightingale P. (2007) The myth of the biotech revolution: An assessment of technological, clinical and organisational change. Research Policy, vol. 36, no 4, pp. 566-589.

Keserü J.(2015) A new approach to measuring the impact of open data. Sunlight Foundation blog, May 5. Available at: https://sunlightfoundation.com/blog/2015/05/05/a-new-approach-to-measuring-the-impact-of-open-data/, accessed 19.08.2016.

Kidwell M.C., Lazarević L.B., Baranski E., Hardwicke T.E., Piechowski S., Falkenberg L.S., Kennett C., Slowik A., Sonnleitner C., Hess-Holden C., Errington T.M., Fiedler S., Nosek B.A. (2016) Badges to acknowledge open practices: A simple, low-cost, effective method for increasing transparency. PLoS Biology, vol. 14, no 5, e1002456. DOI: 10.1371/journal.pbio. 1002456. Available at: http://journals.plos.org/plosbiology/article/file?id=10.1371/journal. pbio.1002456\&type=printable, accessed 19.08.2016.

Kleiner S., Horton R. (2014) How should medical science change? Lancet, vol. 383, no 9913, pp. 197-198.

Lateral Economics (2016) Permission granted: The economic value of data assets under alternative policy regimes. A Lateral Economics report for the Open Data Institute. Available at: https://www.scribd.com/document_downloads/30 9810679? extension=pdf\&from $=$ embed\&source=embed, accessed 21.03.2017.

Macleod M.R., Michie S., Roberts I., Dirnagl U., Chalmers I., Ioannidis J.P.A., Salman R.A., Chan A., Glasziou P. (2014) Biomedical research: Increasing value, reducing waste. Lancet, vol. 383, no 9912, pp. 101-104.

Manville C., Morgan Jones M., Frearson M., Castle-Clarke S., Henham M.-L., Gunashekar S., Grant J. (2015) Preparing impact submissions for REF 2014: An evaluation, findings and observations, Santa Monica, CA: RAND Corporation. Available at: http://www.rand.org/pubs/research_reports/RR727.html, accessed 21.03.2017.

Marjanovic S., Robin E., Lichten C.A., Harte E., MacLure C., Parks S., Horvath V., Côté G., Roberge G., Rashid M. (2015) A Review of the Dementia Research Landscape and Workforce Capacity in the United Kingdom, Santa Monica, CA: RAND Corporation. Available at: http://www.rand.org/content/dam/rand/pubs/research_reports/RR1100/RR1186/ RAND_RR1186, accessed 19.08.2016.

Marshall E. (2012) Patents. U.S. appeals court hears gene patent arguments. Science, vol. 337, no 6092 (July 20), pp. 277-278. DOI: 10.1126/science.337.6092.277.

McKiernan E.C., Bourne P.E., Brown C.T., Buck S., Kenall A., Lin J., McDougall D., Nosek B.A., Ram K., Soderberg C.K., Spies J.R. (2016) How open science helps researchers succeed. eLife, vol. 5, e16800. DOI: 10.7554/eLife.16800. Available at: https://www.ncbi.nlm.nih.gov/pmc/articles/PMC4973366/, accessed 21.03.2017.

Moedas C. (2015) Open Innovation, Open Science, Open to the World. Paper presented at the "A new start for Europe: Opening to an ERA of Innovation" Conference, 22 June 2015, Brussels, SPEECH-15-5243. Available at: http://europa. eu/rapid/press-release_SPEECH-15-5243_en.htm, accessed 19.08.2016.

Morgan Jones M., Castle-Clarke S., Brooker D., Nason E., Huzair F., Chataway J. (2014) The Structural Genomics Consortium. A knowledge platform for drug discovery, Santa Monica, CA: RAND Corporation. Available at: http://www. rand.org/content/dam/rand/pubs/research_reports/RR500/RR512/RAND_RR512.pdf, accessed 19.08.2016.

Nelson R.R. (2004) The Market Economy and the Scientific Commons. Research Policy, vol. 33, pp. 455-471.

NESTA (2007) How innovation happens in six "low innovation" sectors, London: NESTA.

Netherlands EU Presidency (2016) Amsterdam Call for Action on Open Science (Publication of the Netherlands Presidency of the Council of the European Union, May 7, 2016). Available at: http://english.eu2016.nl/binaries/eu2016-en/ documents/reports/2016/04/04/amsterdam-call-for-action-on-open-science/amsterdam-call-for-action-on-openscience.pdf, accessed 19.08.2016.

Open Science Collaboration (2015) Estimating the reproducibility of psychological science. Science, vol. 349, no 6251, pp. aac4716 - aac 4716. DOI: $10.1126 /$ science.aac4716.

Owen G., Hopkins M. (2016) Science, the state and the city: Britain's struggle to succeed in biotechnology, Oxford: Oxford University Press.

Owen-Smith J., Powell W.W. (2003) The Expanding Role of University Patenting in the Life Sciences: Assessing the Importance of Experience and Connectivity. Research Policy, vol. 32, no 9, pp. 1695-1711.

Savage N. (2016) Competition: Unlikely Partnerships. Nature, vol. 533, no 7602, pp. S56-S58. DOI: 10.1038/533S56a.

Smith E., Gunashekar S., Parks S., Lichten C., Lepetit L., Morgan Jones M., Manville C., MacLure C. (2017) Monitoring Open Science Trends in Europe, Santa Monica, CA: RAND Corporation. Available at: https://www.rand.org/pubs/tools/ TL252.html, accessed 19.06.2017.

Stern N. (2016) Building on Success and Learning from Experience. An Independent Review of the Research Excellence Framework, London: Department for Business, Energy \& Industrial Strategy of the UK Government.

Swan A., Gargouri Y., Hunt M., Harnad S. (2015) Open Access Policy: Numbers, Analysis, Effectiveness. Pasteur4OA Workpackage 3 Report, Brussels: European Comission. Available at: https://arxiv.org/ftp/arxiv/papers/1504/1504.02261. pdf, accessed 19.08.2016.

Tait J., Chataway J. (2007) The governance of corporations, technological change, and risk: Examining industrial perspectives on the development of genetically modified crops. Environment and Planning C: Government and Policy, vol. 25, pp. 21-37.

Taylor J., Marjanovic S., Nolte E., Pollitt A., Rubin J. (2015) Treatment for dementia: Learning from breakthroughs for other conditions, Santa Monica, CA: RAND Corporation. Available at: http://www.rand.org/pubs/research_reports/RR909. html, accessed 19.08.2016.

Van den Eynden V., Bishop L. (2014) Incentives and motivations for sharing research data: A researcher's perspective, Colchester (UK): University of Essex. Available at: http://www.knowledge-exchange.info/event/sowing-the-seed, accessed 19.08.2016.

Vincent-Lamarre P., Boivin J., Gargouri Y., Larivière V., Harnad S. (2016) Estimating open access mandate effectiveness: The MELIBEA Score. Journal of the Association for Information Science and Technology, vol. 67, no 11, pp. 2815-2828. DOI: 10. 1002/asi.23601. Available at: https://arxiv.org/ftp/arxiv/papers/1410/1410.2926.pdf, accessed 18.03.2017.

Yozwiak N.L., Schaffner S.F., Sabeti P.C. (2015) Make outbreak research open access. Nature, vol. 518, no 7540, pp. 477-479. 